\section{Biliary peritonitis, due to rupture of intrahepatic duct}

Sir,

We would like to report our experience of a patient with biliary peritonitis due to rupture of intrahepatic biliary ducts.

A 65 year old male patient presented with the complaints of pain and distension of abdomen for 3 days. Following examination, a diagnosis of peritonitis with shock was made. Resuscitative measures were started and with improvement in his general condition, an exploratory laparotomy was performed. Approximately 2.5 litres of bile stained fluid were sucked out from the peritoneal cavity. A growth occupying the proximal 1/3rd of the stomach, causing complete occlusion of the stomach lumen, was found. During the search for possible metastasis, two ulcers were found on the superior surface of the left lobe of the liver. Bile was seen oozing from the floor of the ulcers. The extrahepatic biliary ducts, gall bladder and duodenum were normal. A biopsy was taken from the ulcer margins, but revealed no evidence of malignancy. The patient expired on the second post-operative day.

Nauwerk $^{1}$ in 1905 first recorded 2 fatal cases of bile peritonitis, each of which at autopsy, proved to have a minute perforation on the surface of the liver. Since then 17 more cases of intrahepatic biliary duct perforation have been added. ${ }^{2,3}$

Most intrahepatic duct perforations have been seen in elderly female patients. Pre-operative diagnosis of spontaneous perforation of biliary ducts is exceedingly difficult. $^{3}$ Biliary peritonitis has a very high mortality rate $(30-50 \%) .{ }^{4}$ The present case differs from the earlier cases reported in that spontaneous perforation of intrahepatic ducts occurred in the absence of any apparent common bile duct obstruction, and there were two perforations (ulcers) from which the bile leak was taking place. The cause of the perforation was probably secondary metastasis from carcinoma of the stomach infiltrating the intrahepatic ducts.

Habib Md. Raza

Anwar Md. Hussain Department of Surgery and Pathology, J.N. Medical College, Aligarh Muslim University, Aligarh (U.P.), India.

\section{References}

1. Nauwerk, C. Rupture der Leber durch Gallenstauung. Miinch Med Wochenschr 1905, 52: 931-932.

2. Smith, W. Rupture of an intrahepatic bile duct with fatal peritonitis. Ann Surg 1926, 83: 55-68.

3. Susuma Nobusawa, Takenori Adachi, Akira Miyazki et al. A case report of biliary peritonitis - spontaneous perforation of an intrahepatic duct. Am J Gastroenterol 1986, 81: 568-571.

4. Donald, J.W. \& Ozment, E.D. Spontaneous perforation of bile ducts. Am Surg 1977, 43: 524-527.

\section{Hyperimmunoglobulinaemia D and periodic fever mimicking familial mediterranean fever in the Mediterranean}

Sir,

We have seen two Turkish patients in the paediatric age group with hyperimmunoglobulinaemia $\mathbf{D}$ and periodic fever syndrome resembling familial mediterranean fever (FMF). This syndrome was first reported by Van der Meer $^{1}$ and, subsequently, by Reeves ${ }^{2}$ in 1984 . In 1988 Ostuni reported another case. ${ }^{3}$

Our first patient was a 10 year old girl who initially had recurrent fevers preceded by chills, transient erythematous rashes, arthralgia. diarrhoea, which sometimes coincided with the fever attacks, since 5 years of age. On physical examination she had multiple cervical microlymphadenopathy. Her blood serology was as follows: $\mathrm{C}_{3}, \mathrm{C}_{4}$ levels were normal, rheumatoid factor, ANA, antiDNA, LE cell were negative. A skin biopsy revealed capillaritis. Immunoelectrophoresis showed high IgD level (220 IU/1) (normal adult $<150 \mathrm{IU} / \mathrm{l})$. She was put on colchicine, with a diagnosis of hyperimmunoglobulinaemia $\mathbf{D}$ and periodic fever syndrome, with little benefit.

Our second patient was a 9 year old girl. She presented with recurrent fevers and abdominal pain, transient erythematous rashes, arthralgia and diarrhoea attacks since age 5 . She had postauricular lymphadenopathy. Her $\mathrm{C}_{3}$ and $\mathrm{C}_{4}$ levels were slightly elevated, $\mathrm{CH}_{50}$, cryoglobulins, ANA, and fibrinogen were normal. Bone marrow aspiration showed erythroid hyperplasia. Skino biopsy was consistent with nonspecific dermatitis. Her IgD level was elevated at $22 \mathrm{mg} / \mathrm{dl}$ (normal adultô $<14 \mathrm{mg} / \mathrm{dl}$ ). A diagnosis of hyperimmunoglobulinaemia $D$ and periodic fever syndrome was made and a course of colchicine was tried, without much improvement.

IgD is a membrane-bound immunoglobulin as an antigen receptor regulation of $B$ cell development. IgD neither crosses the placenta nor is synthesized in significant quantities by the newborn. It reaches adult levels by age $15{ }^{2,3}$ Elevated IgD levels in disease are only rarely observed. ${ }^{4}$ Increased IgD levels have been reported in Hodgkin's disease, ataxia telangiectasia, infection with human immune deficiency viruses and recurrent bacterial infections. ${ }^{2,5-7}$ Both our patients were under 15 years of age. They had elevated levels of IgD with the symptoms mimicking FMF but differing from it in several respects, such as predominance of fever with chills rather than abdominal pain. Also lymphadenopathy and diarrhoea occasionally coincided with attacks as reported before. ${ }^{1,2}$

All reported hyperimmunoglobulinaemia $D$ and periodic fever syndrome patients are of nonMediterranean origin. ${ }^{1,2}$ Our Turkish cases show that this disease should be kept within the differential diagnosis of FMF even in parts of the world where FMF is more common. Also, the benefit of colchicine regimen in these patients is unclarified. ${ }^{1,2}$

Rezan Topaloğlu Ümit Saatçi

Department of Paediatric Nephrology, Hacettepe Children's Hospital, 06100, Ankara, Turkey. 


\section{References}

1. Van der Meer, J.W.S., Vossen, J.M., Radl, J. et al. Hyperimmunoglobulinaemia $D$ and periodic fever: a new syndrome. Lancet 1984, i: 1087-1090.

2. Reeves, W.G. \& Mitchell, J.R.A. Hyperimmunoglobulinaemia $\mathrm{D}$ and periodic fever. Lancet 1984, i: 1463-1464.

3. Ostuni, P.A., Lazzarin, P., Ongaro, G., Gussi, R., Todesco, S. \& Gambari, P.F. Hyper-IgD syndrome: a new case treated with colchicine. Clin Rheumatol 1988, 7: 398-401.

4. Saxon, A. \& Stiehm, E.R. The B lymphocyte system: In: Stiehm, E.R. (ed.) Immunologic Disorders in Infants and Children. W.B. Saunders, Philadelphia, 1989, pp. 53, 63.

5. Leslie, G.A. \& Martin, L.N. Structure and function of serum and membrane IgD. In: Reisfeld, R.A. \& Inman, F.P. (eds) Contemporary Topics in Molecular Immunology. Plenum Press, New York, 1979, p.13.

6. Corte, G., Ferrarini, M., Tonda, P. \& Bargellesi, A. Increased serum IgD concentation in patients with Hodgkin's disease. Clin Exp Immunol 1977, 28: 359-362.

7. Mizuma, H., Zolla-Pazner, S., Litwin, S. et al. Serum IgD elevation is an early marker of B cell activation during infection with human immunodeficiency viruses. Clin Exp Immunol 1987, 68: 5-14.

8. Radl, J., Masapust, J. \& Lackova, E. Selective hyperimmunoglobulinaemia A and D in a case with chronic generalized eczama and prolonged sepsis. Helv Pediatr Acta 1967, 22: 278-288.

\section{Multiple pulmonary infarctions caused by giant cell arteritis}

Sir,

A previously healthy 83 year old woman presented with a 4-week history of dyspnoea, weight loss, malaise and headaches. Apart from dyspnoea, systems examination revealed no positive physical signs. ESR was $80 \mathrm{~mm}$ in 1 hour. Haemoglobin, white cell count, blood glucose, urea, electrolytes, urinary microscopy, chest radiograph and ECG were all normal. Auto-antibody screen was negative. Giant cell arteritis was diagnosed and temporal artery biopsy showed florid inflammation of full thickness of vessel wall, infiltrated by lymphocytes, macrophages and numerous giant cells with fibroblastic connective tissue proliferation of the intima. Prednisolone $60 \mathrm{mg} /$ day was commenced and the response was dramatic with complete remission of all her symptoms, including dyspnoea. The ESR decreased to $2 \mathrm{~mm}$ in 1 hour.

Two months later prednisolone was gradually reduced to $15 \mathrm{mg} /$ day, following which dyspnoea recurred and progressively worsened, necessitating her hospitalization. There was no evidence of deep vein thrombosis, nor were there any new physical signs. ESR rose to $93 \mathrm{~mm}$ in 1 hour. ECG, chest radiograph and serum biochemistry all remained normal. Ventilation and perfusion lung scan were consistent with multiple pulmonary infarctions. Prednisolone was increased to $40 \mathrm{mg} /$ day and she was initially anticoagulated. Dyspnoea improved over the following 4 weeks and she remained asymptomatic with ESR of $11 \mathrm{~mm}$ in 1 hour 4 months after her discharge from the hospital.

All the initial symptoms in this patient except the dyspnoea were typical of giant cell arteritis. The cause of dyspnoea was unclear at the initial presentation. Dysp- noea, along with other symptoms, responded well to steroid therapy but recurred and progressively increased on reduction of steroid dose.

Giant cell arteritis is a multisystem disease but pulmonary involvement is rare. A few cases of pulmonary nodules and interstitial infiltrates resolving with steroid therapy have been reported in association with giant cell arteritis.' Lung biopsies in some such cases showed interstitial, non-caseating granulomas. ${ }^{2}$

The histology of a lobectomy specimen in a suspected case of carcinoma of bronchus showed no tumour but revealed areas of infarction, fibrosis and features of giant cell arteritis of pulmonary artery. ${ }^{3}$ Aneurysm and narrowing of pulmonary artery due to giant cell arteritis have separately been reported in two cases. 4,5

The striking response of dyspnoea to steroid therapy, its recurrence on reducing steroid dose and the absence of predisposing factors make pulmonary embolism as the aetiology most unlikely. On the other hand these features strongly favour giant cell arteritis of pulmonary arteries as the cause of pulmonary infarction. Giant cell arteritis, if diagnosed and treated early, has a good prognosis for complete recovery. Therefore physicians should be aware of pulmonary infarction as a complication in patients with giant cell arteritis with respiratory symptoms.

M. Radhamanohar Charing Cross Hospital, London W6, UK.

\section{References}

1. Kramer, M.R., Melzer, E., Nesher, G. \& Sonnenblick, M. Pulmonary manifestations of temporal arteritis. Eur $J$ Respir Dis 1987, 71: 430-433.

2. Karam, G.H. \& Fulmer, J.D. Giant cell arteritis presenting as interstitial lung disease. Chest 1982, 82: 781-784.

3. Doyle, L., McWilliam, L. \& Hasleton, P.S. Giant cell arteritis with pulmonary involvement. Br J Ris Chest 1988, 82: 88-92.

4. Dennison, A.R., Watkins, R.M. \& Gunning, A.J. Simultaneous aortic and pulmonary artery aneurysms due to giant cell arteritis. Thorax 1985, 40: 156-157.

5. Wagenaar, S.S.C., Westerman, C.J.J. \& Corrin, B. Giant cell arteritis limited to large elastic pulmonary arteries. Thorax 1981, 36: 876-877.

\section{Serial neopterin concentrations in disseminated T-cell lymphoma}

Sir,

Neopterin, a pyrazine $(2,3 \mathrm{~d})$ pyrimidine derivative, is synthesized by mammalian cells as a degradation product of dihydroneopterin triphosphate, an intermediate in the synthesis of tetrahydrobiopterin which is the essential cofactor in the hydroxylations of phenylalanine, tyrosine and tryptophan. The macrophage is uniquely unable to convert dihydroneopterin triphosphate to tetrahydrobiopterin, the pathway being diverted to neopterin which is produced in increased quantity when macrophages are stimulated by gamma interferon released by activated T-cells. 